\title{
Identifying youth at high risk for sexually transmitted infections in community-based settings using a risk prediction tool: a validation study
}

Katharina Kranzer ${ }^{1,2,3^{*}}$, Victoria Simms ${ }^{2,4}$, Ethel Dauya ${ }^{2}$, loana D. Olaru ${ }^{1,2}$, Chido Dziva Chikwari ${ }^{1,2}$, Kevin Martin $^{1,5}$, Nicol Redzo ${ }^{2}$, Tsitsi Bandason², Mandikudza Tembo ${ }^{2,4}$, Suzanna C. Francis ${ }^{4}$, Helen A. Weiss ${ }^{4}$, Richard J. Hayes ${ }^{4}$, Constancia Mavodza ${ }^{2,6}$, Tsitsi Apollo7, Gertrude Ncube ${ }^{7}$ Anna Machiha ${ }^{7}$ and Rashida Abbas Ferrand ${ }^{1,2}$

\begin{abstract}
Background: Chlamydia trachomatis (CT) and Neisseria gonorrhoeae (NG) are the most common bacterial sexually transmitted infections (STIs) worldwide. In the absence of affordable point-of-care STI tests, WHO recommends STI testing based on risk factors. This study aimed to develop a prediction tool with a sensitivity of $>90 \%$ and efficiency (defined as the percentage of individuals that are eligible for diagnostic testing) of $<60 \%$.

Methods: This study offered CT/NG testing as part of a cluster-randomised trial of community-based delivery of sexual and reproductive health services to youth aged 16-24years in Zimbabwe. All individuals accepting STI testing completed an STI risk factor questionnaire. The outcome was positivity for either CT or NG. Backwards-stepwise logistic regression was performed with $p \geq 0.05$ as criteria for exclusion. Coefficients of variables included in the final multivariable model were multiplied by 10 to generate weights for a STI risk prediction tool. A maximum likelihood Receiver Operating Characteristics (ROC) model was fitted, with the continuous variable score divided into 15 categories of equal size. Sensitivity, efficiency and number needed to screen were calculated for different cut-points.

Results: From 3 December 2019 to 5 February 2020, 1007 individuals opted for STI testing, of whom 1003 (99.6\%) completed the questionnaire. CT/NG prevalence was $17.5 \%(95 \% \mathrm{Cl} 15.1,19.8)(n=175)$. CT/NG positivity was independently associated with being female, number of lifetime sexual partners, relationship status, HIV status, selfassessed STI risk and past or current pregnancy. The STI risk prediction score including those variables ranged from 2 to 46 with an area under the ROC curve of $0.72(95 \% \mathrm{Cl} 0.68,0.76)$. Two cut-points were chosen: (i) 23 for optimised sensitivity (75.9\%) and specificity (59.3\%) and (ii) 19 to maximise sensitivity (82.4\%) while keeping efficiency at $<60 \%$ (59.4\%).
\end{abstract}

Conclusions: The high prevalence of STIs among youth, even in those with no or one reported risk factor, may preclude the use of risk prediction tools for selective STI testing. At a cut-point of 19 one in six young people with STIs would be missed.

\footnotetext{
*Correspondence: katharina.kranzer@Ishtm.ac.uk

${ }^{1}$ Clinical Research Department, Faculty of Infectious and Tropical

Diseases, London School of Hygiene and Tropical Medicine, London, UK

Full list of author information is available at the end of the article
} original author(s) and the source, provide a link to the Creative Commons licence, and indicate if changes were made. The images or other third party material in this article are included in the article's Creative Commons licence, unless indicated otherwise in a credit line to the material. If material is not included in the article's Creative Commons licence and your intended use is not permitted by statutory regulation or exceeds the permitted use, you will need to obtain permission directly from the copyright holder. To view a copy of this licence, visit http://creativecommons.org/licenses/by/4.0/. The Creative Commons Public Domain Dedication waiver (http://creativeco mmons.org/publicdomain/zero/1.0/) applies to the data made available in this article, unless otherwise stated in a credit line to the data. 
Keywords: Sexually transmitted infections, Adolescents, Screening, Risk prediction tool

\section{Introduction}

Chlamydia trachomatis and Neisseria gonorrhoeae are the most common bacterial sexually transmitted infections (STIs) worldwide. These conditions have important sexual, reproductive, and maternal-child health consequences, including genital symptoms, pregnancy complications, infertility, enhanced HIV transmission, and psychological effects [1-8]. Importantly both chlamydia and gonorrhoea are curable with well-tolerated shortcourse antibiotics.

In 2016, there were an estimated 127.2 million (95\% uncertainty interval (UI): 95.1-165.9 million) chlamydia and 86.9 million (95\% UI: 58.6-123.4 million) gonorrhoea infections globally, with prevalence varying by World Health Organization (WHO) region [9]. Chlamydia prevalence estimates among 15-49year olds in the African region are the second highest globally at 5.0\% (95\% UI: 3.8-6.6) in women and 4.0\% (95\% UI: 2.4-6.1) in men. The African region is estimated to have the highest prevalence of gonorrhoea globally with a prevalence of $1.9 \%$ (95\% UI: 1.3-2.7) in women and 1.6\% (95\% UI: 0.9-2.6) in men. Systematic reviews focusing on women in sub-Saharan Africa revealed a prevalence of chlamydia of $3.3-7.8 \%$ and gonorrhoea of $2.2-4.2 \%$ [10, 11]. However, comparable data for men are scarce. Notably, youth are at much higher risk of STIs than adults [9, 12-14]. An individual participant data meta-analysis including women participating in $18 \mathrm{HIV}$ prevention studies in sub-Saharan Africa recruited mostly before 2010 showed that chlamydia and gonorrhoea prevalence was generally higher among the 15-24year olds compared to the 25-49 year olds [15].

The WHO Global Health Sector Strategy on STIs 2016-2021 (Global Strategy), provides goals, targets, and priority actions for curtailing the STI epidemic [16]. A priority action for countries is the implementation and scale-up of services aimed at early diagnosis of STIs to ensure effective medical treatment and prevent further transmission. Early diagnosis of STIs is challenging, given that most STIs are asymptomatic especially in women [17-19]. In the absence of affordable point-of-care tests for STIs, universal screening remains rare in resourceconstrained settings. An approach promoted by WHO is to offer STI testing to asymptomatic individuals based upon risk factors or risk prediction tools [16].

Clinical prediction rules for STIs have been successfully developed for high-income settings to allow for a so-called "selective screening" approach [20, 21]. This approach is aimed at minimising costs associated with testing low-risk individuals while detecting most infections. Thresholds of $60 \%$ efficiency (defined as percentage of individuals that are eligible for diagnostic testing based on predictive criteria) and $90 \%$ sensitivity have been proposed as ideal benchmarks for clinical prediction tools in the context of STIs [20, 22, 23].

Previous STI risk prediction tools administered by healthcare providers in Africa have been developed using an ad-hoc approach and were found to have a poor sensitivity; none have been developed specifically for youth $[19,24]$. We aimed to develop a clinical prediction tool for STIs specifically targeting youth in Zimbabwe.

\section{Methods \\ Study design and setting}

This study was nested within a cluster-randomised trial (CHIEDZA) of an integrated package of HIV and sexual and reproductive health (SRH) services for youth delivered in community-based settings in Zimbabwe (registered in clinical trials.gov: NCT03719521). Individuals aged 16-24years living within an intervention cluster are eligible to receive an integrated package of SRH services including HIV testing, HIV treatment and adherence support, contraception, pregnancy testing, syndromic management of STIs, menstrual health information and products, condoms and general health counselling. Individuals older than 24 years of age at a repeat visit, who were less than 25 years at the first visit are also eligible to accessing the services. Testing for gonorrhoea and chlamydia was offered to all clients accessing CHIEDZA services over a limited period of time. Treatment of STIs and HIV is provided according to national guidelines. All services are offered free of charge.

The trial is being conducted in three provinces (Harare, Mashonaland East and Bulawayo), with each province containing eight geographically demarcated clusters randomised 1:1 to four intervention and four standard of care (routine, existing services) clusters. The intervention is delivered once weekly (on the same day each week) at a community centre in each intervention cluster by a team of nurses, community health workers, youth workers and a counsellor.

This sub-study assessing STI risk factors was conducted in eight intervention clusters in Harare and Mashonaland East.

\section{STI testing}

All individuals accessing CHIEDZA services were nonselectively offered testing for gonorrhoea and chlamydia 
if they had not tested within the 6 months prior to the visit, regardless of whether they had symptoms or risk factors for STIs. Those who accepted testing were asked to provide a urine sample which was tested using the GeneXpert platform (Cepheid, Sunnyvale, CA, USA) [9]. All individuals were given the option to pick up their result the following week, and individuals with a positive result were actively contacted by phone and asked to visit the centre. Positive test results were not disclosed over the phone, but only provided face to face. Partner notification (PN) slips were given to those who had a positive STI test result and all partners were offered treatment. Individuals who reported STI symptoms were treated according to national guidelines for syndromic management but were also offered testing for gonorrhoea and chlamydia [25].

\section{Risk factors for STIs}

All individuals accepting STI testing were approached by the study team and asked if they would like to participate in the risk factor sub-study. Those consenting were asked to answer a short questionnaire (11 items) regarding current relationship status, number of sexual partners, concurrent partners, condom use, use of contraception, previous or current pregnancies and STI risk perception. HIV status was obtained from the CHIEDZA dataset. The questions in the questionnaire were informed by studies developing risk prediction tools for chlamydia and gonorrhoea infection in high-income settings [20, $21]$ and studies investigating risk factors for those infections in sub-Saharan Africa [13, 17, 19, 24, 26, 27]. The questionnaire was administered by a research assistant not involved in STI testing or delivering other CHIEDZA services.

\section{Data analysis}

The outcome was positivity for either C. trachomatis or $N$. gonorrhoeae, combined as one variable. For variables that only applied to women (past pregnancy and use of hormonal contraception) males were coded 'no' for multivariable analysis. Univariable logistic regression was used to estimate the odds ratios (OR) and 95\% confidence intervals $(95 \% \mathrm{CI})$ for the association between STI infection and each of the 11 risk factors determined by the questionnaire and HIV status, age and sex. Variables that were associated with the outcome at $10 \%$ significance level in the univariable analysis were included in a multivariable model and then removed sequentially using backwards stepwise logistic regression until all remaining variables were associated with the outcome at $<5 \%$ significance. For ordinal variables p-values were calculated with a Wald test. Coefficients of variables included in the final multivariable model were multiplied by 10 to generate weights, and the weights were added for each individual to create an STI risk score. A maximum likelihood Receiver Operating Characteristic (ROC) model was fitted, with the continuous score variable divided into 15 categories of equal size. All possible cut-points of the risk prediction tool were evaluated for sensitivity, specificity, efficiency (proportion of the sample who screen positive) and number needed to test to obtain one positive result.

From a pilot study, the prevalence of the outcome was estimated at $17 \%$ [28]. A sample size of 1000 gave $80 \%$ power to detect a risk ratio of 1.7 for a risk factor with $10 \%$ prevalence, and $80 \%$ power to detect a risk ratio of 2.0 for a risk factor with $5 \%$ prevalence.

\section{Results}

Between 3 December 2019 and 5 February 2020; 1007 individuals opted for STI testing of whom 1003 gave consent for data on risk factors to be collected. The majority of these were female $(78.7 \%, \mathrm{n}=789)$ and aged $20-24(58.2 \%, \mathrm{n}=584)$ years, similar to the demographic profile of those accessing CHIEDZA services. HIV status was known for 957 participants, among whom HIV prevalence was $5.2 \%(\mathrm{n}=50)$. Of these, $36(72.0 \%)$ were previously diagnosed and taking antiretroviral therapy (ART), and $14(28.0 \%)$ were newly diagnosed through CHIEDZA.

Prevalence of C. trachomatis and/or N. gonorrhoeae infection was $17.5 \%$ (95\% CI 15.1-19.8) $(\mathrm{n}=175)$, of whom $14.8 \%$ (95\% CI 12.6-17.1) $(\mathrm{n}=148)$ tested positive for C. trachomatis and 4.1\% $(\mathrm{n}=41)(95 \%$ CI 2.9-5.5) for $N$. gonorrhoeae, with $1.4 \%(\mathrm{n}=14)$ testing positive for both infections. In total 39 of the 1003 participants (3.8\%) reported STI symptoms and 21 received syndromic management, of whom 13 subsequently tested positive for either C. trachomatis, $N$. gonorrhoeae or both.

In univariable analysis, older age, being female, being in a relationship or widowed/divorced, number of lifetime sexual partners and number of sexual partners in the past three months, having had a new sexual partner in the past three months, history of STI treatment, history of STI treatment of the partner, occasional condom use, perceived high STI risk, positive HIV status and past or current pregnancy were all associated with having an STI $(\mathrm{p}<0.1$; Table 1$)$. The multivariable analysis including all these variables showed an independent significant association between STI infection and being female, relationship status, number of lifetime sexual partners, HIV status, perceived STI risk and past or current pregnancy. These variables were included in the final multivariable model. Odds ratios for associations between risk factors and having an STI ranged between 1.23 and 3.98 (Table 1). 
Table 1 Logistic regression models for association of risk factors with STI prevalence

\begin{tabular}{|c|c|c|c|c|c|c|c|c|}
\hline \multirow[t]{2}{*}{ Variable } & & \multirow{2}{*}{$\begin{array}{l}\text { N with STI/ } \\
\text { total N (STI } \\
\text { prevalence) }\end{array}$} & \multicolumn{2}{|l|}{ Univariable } & \multicolumn{2}{|c|}{$\begin{array}{l}\text { Multivariable } 1 \\
(\mathrm{~N}=957)\end{array}$} & \multicolumn{2}{|l|}{$\begin{array}{l}\text { Multivariable } 2 \\
(\mathrm{~N}=957)\end{array}$} \\
\hline & & & OR $(95 \% \mathrm{Cl})$ & $p$ & OR & $p$ & OR & $\mathrm{p}$ \\
\hline \multirow[t]{2}{*}{ Age group } & $16-19$ & $61 / 419(14.6)$ & 1 & 0.042 & 1 & 0.95 & & \\
\hline & $20-25$ & $114 / 584(19.5)$ & $1.42(1.01,2.00)$ & & $\begin{array}{l}1.01(0.68, \\
1.51)\end{array}$ & & & \\
\hline \multirow[t]{2}{*}{ Sex } & Male & $23 / 214(10.8)$ & 1 & 0.004 & 1 & 0.001 & 1 & 0.001 \\
\hline & Female & $152 / 789(19.3)$ & $1.98(1.24,3.16)$ & & $\begin{array}{l}2.77(1.54 \\
4.98)\end{array}$ & & $2.64(1.52,4.57)$ & \\
\hline \multirow[t]{4}{*}{ Relationship status } & Single & 21/177 (11.9) & $0.65(0.39,1.10)$ & 0.005 & $\begin{array}{l}1.48(0.72, \\
3.04)\end{array}$ & 0.02 & $1.23(0.67-2.27)$ & 0.007 \\
\hline & Boyfriend/girlfriend & 70/368 (19.0) & $1.14(0.80,1.64)$ & & $\begin{array}{l}1.82(1.05 \\
3.12)\end{array}$ & & $1.70(1.09-2.63)$ & \\
\hline & Married & $74 / 434(17.1)$ & 1 & & 1 & & 1 & \\
\hline & Divorced/widowed & 10/24 (41.7) & $3.47(1.49,8.12)$ & & $\begin{array}{l}4.10(1.50 \\
11.25)\end{array}$ & & $3.71(1.51-9.06)$ & \\
\hline \multirow[t]{2}{*}{$\begin{array}{l}\text { New partner in the last } \\
3 \text { months }\end{array}$} & Yes & $35 / 157(22.3)$ & $1.45(0.95,2.20)$ & 0.083 & $\begin{array}{l}0.69(0.36 \\
1.30)\end{array}$ & 0.25 & & \\
\hline & No & $129 / 846(16.6)$ & 1 & & 1 & & & \\
\hline \multirow{3}{*}{$\begin{array}{l}\text { No of sexual partners in last } \\
3 \text { months }\end{array}$} & 0 & $31 / 293(10.6)$ & 1 & $<0.001$ & 1 & 0.16 & & \\
\hline & 1 & $119 / 623(19.1)$ & $2.00(1.31,3.04)$ & & $\begin{array}{l}1.07(0.54, \\
2.12)\end{array}$ & & & \\
\hline & $2+$ & 25/87 (28.7) & $3.41(1.88,6.18)$ & & $\begin{array}{l}2.09(0.83 \\
5.25)\end{array}$ & & & \\
\hline \multirow[t]{3}{*}{ No of lifetime partners } & 0 & 11/186 (5.9) & 1 & & 1 & 0.004 & 1 & \\
\hline & 1 & $54 / 388(13.9)$ & $2.57(1.31,5.04)$ & $<0.001$ & $\begin{array}{l}2.19(0.85 \\
5.64)\end{array}$ & & $2.09(0.98,4.44)$ & $<0.001$ \\
\hline & $2+$ & $110 / 429(25.6)$ & $5.49(2.87,10.47)$ & & $\begin{array}{l}3.89(1.47 \\
10.29)\end{array}$ & & $3.98(1.93,8.19)$ & \\
\hline \multirow[t]{2}{*}{ History of STI treatment } & Yes & 22/79 (27.9) & $1.94(1.15,3.28)$ & 0.012 & $\begin{array}{l}0.75(0.40, \\
1.40)\end{array}$ & 0.36 & & \\
\hline & No & 153/924 (16.6) & 1 & & 1 & & & \\
\hline \multirow[t]{2}{*}{ Partner ever had an STI } & Yes & $17 / 43(39.5)$ & $3.32(1.76,6.26)$ & $<0.001$ & $\begin{array}{l}1.90(0.88, \\
4.07)\end{array}$ & 0.10 & & \\
\hline & No & $158 / 960(16.5)$ & 1 & & 1 & & & \\
\hline \multirow[t]{2}{*}{ HIV status $(\mathrm{N}=957)$} & Positive & $18 / 50(36.0)$ & $2.79(1.53,5.11)$ & $<0.001$ & $\begin{array}{l}2.05(1.05 \\
4.01)\end{array}$ & 0.04 & $1.95(1.02,3.72)$ & 0.04 \\
\hline & Negative & 152/907 (16.8) & 1 & & 1 & & 1 & \\
\hline \multirow[t]{3}{*}{ Use of condoms $(\mathrm{N}=817)$} & Always & 15/116 (12.9) & $0.70(0.38,1.28)$ & 0.004 & $\begin{array}{l}0.65(0.32, \\
1.35)\end{array}$ & 0.12 & & \\
\hline & Sometimes & $82 / 319(25.7)$ & $1.63(1.13,2.34)$ & & $\begin{array}{l}1.27(0.81 \\
1.99)\end{array}$ & & & \\
\hline & Never & $67 / 382(17.5)$ & 1 & & 1 & & & \\
\hline \multirow[t]{2}{*}{ Perceived STI risk } & None/low & 93/721 (12.9) & 1 & $<0.001$ & 1 & 0.01 & 1 & $<0.001$ \\
\hline & Medium/high & $82 / 282(29.1)$ & $2.77(1.98,3.88)$ & & $\begin{array}{l}1.67(1.12, \\
2.49)\end{array}$ & & $1.98(1.37,2.87)$ & \\
\hline \multirow{2}{*}{$\begin{array}{l}\text { Use of hormonal contra- } \\
\text { ception }(\mathrm{N}=789)\end{array}$} & Yes & $87 / 451(19.3)$ & $1.00(0.70,1.44)$ & 0.98 & & & & \\
\hline & No & 65/338 (19.2) & 1 & & & & & \\
\hline \multirow[t]{2}{*}{$\begin{array}{l}\text { Past or current pregnancy } \\
(\mathrm{N}=789)\end{array}$} & Yes & $13 / 36(36.1)$ & $2.50(1.23,5.05)$ & 0.011 & $\begin{array}{l}2.70(1.27 \\
5.78)\end{array}$ & 0.01 & $2.55(1.21,5.39)$ & 0.014 \\
\hline & No & 139/753 (18.5) & 1 & & 1 & & 1 & \\
\hline
\end{tabular}




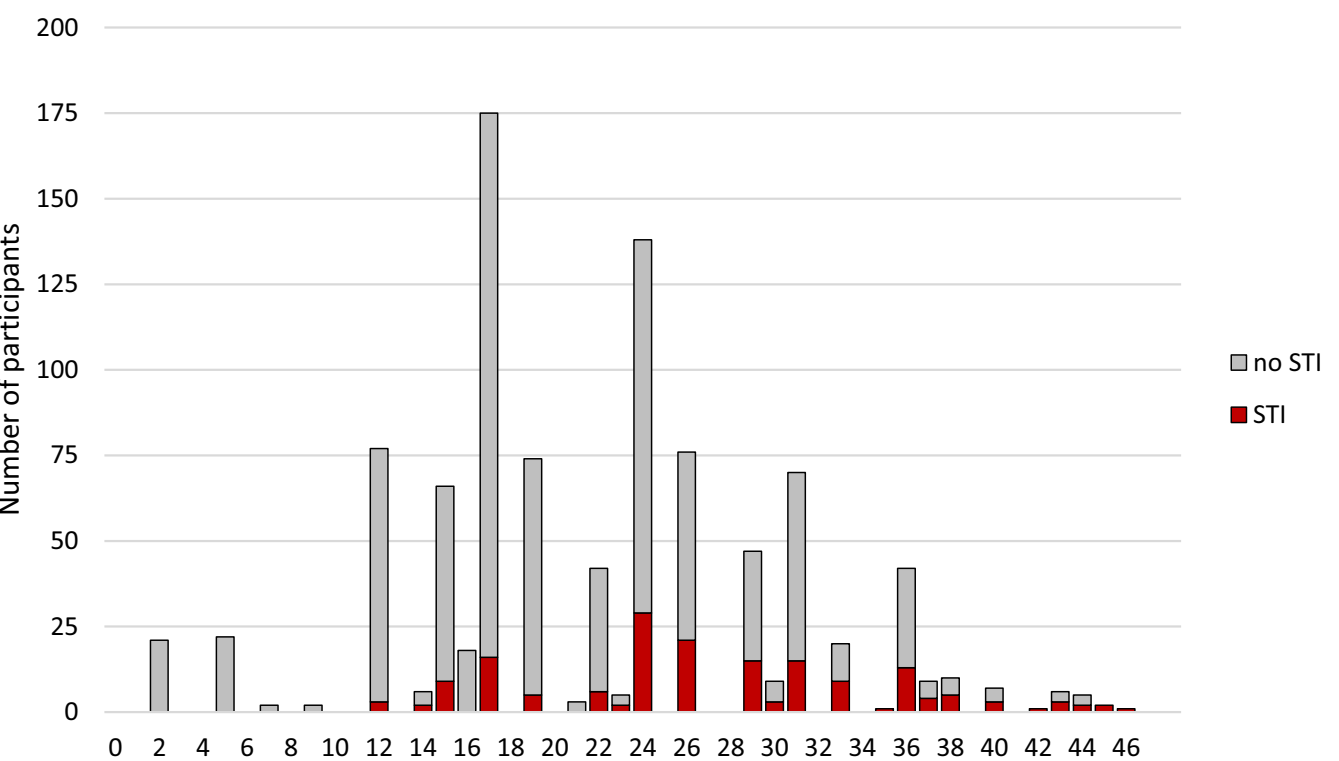

Fig. 1 Distribution of STI risk scores. Red bars: tested positive for STI, grey bar: tested negative for STI, red line: efficiency (proportion scoring at or above the cut-point), grey line: sensitivity, blue line specificity, black dotted line: cut-point of 23

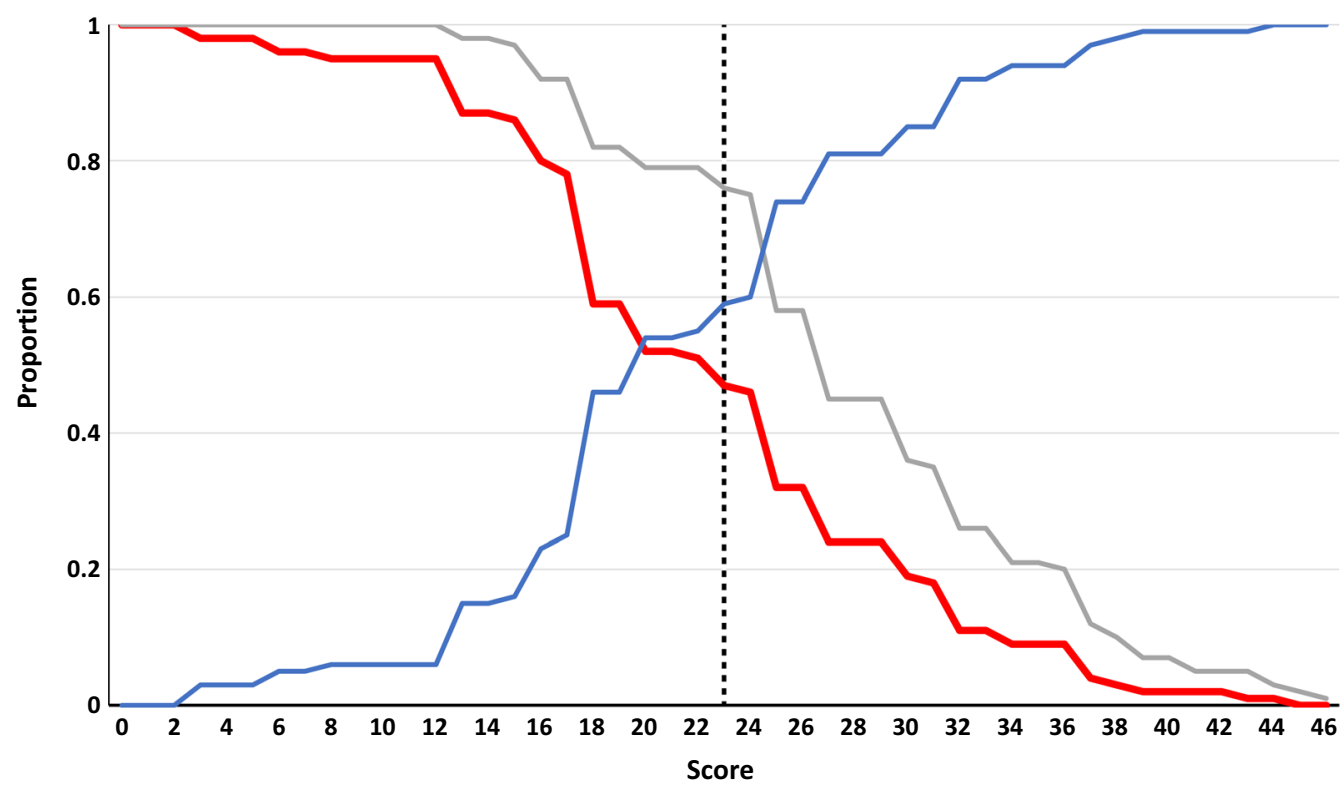

Fig. 2 Sensitivity and specificity of all risk score cut-points. Red line: efficiency (proportion scoring at or above the cut-point), grey line: sensitivity, blue line specificity, black dotted line: cut-point of 23

The STI risk prediction tool generated from the final model is shown in Table 2. The score ranged from 2 for single participants with no other risk factors to 46 for those with all six risk factors (Fig. 1). For example, an HIV negative woman with a boyfriend who had 1 lifetime sexual partner, perceived herself at low risk and had never been pregnant would score $10+5+7=22$. The maximum possible score for males was 41 . A score of 0 would only be possible for a married male with no lifetime sexual partners, which did not occur in the dataset. 
Table 2 STI risk score variable weightings for variables with $p<0.10$ in the final multivariable logistic regression model

\begin{tabular}{lllc}
\hline & & B-Coefficient & Weighting \\
\hline Sex & Female & 0.97 & 10 \\
Relationship status (vs. married) & Single & 0.21 & 2 \\
& Boyfriend/girlfriend & 0.53 & 5 \\
Number of lifetime partners (vs. 0) & Divorced/widowed & 1.31 & 13 \\
HIV status & 1 & 0.74 & 7 \\
Perceived risk of STI & $\geq 2$ & 1.38 & 7 \\
Past pregnancy & Positive & 0.67 & 7 \\
\hline
\end{tabular}

The sensitivity, specificity and efficiency of all possible cut-points is shown in Fig. 2, and the ROC curve with $95 \%$ CI is shown in Fig. 3. The area under the curve is 0.72 . Two cut-points for the risk tool were chosen: 23 for optimised sensitivity (75.9\%) and specificity (59.3\%), and 19 to meet the benchmark of maximising sensitivity (82.4\%) while keeping efficiency $(59.4 \%)$ at less than $60 \%$ (Table 3). The number needed to screen to diagnose one STI was 3.5 for a cut-point of 23 and 4.1 for a cut-point of 19.

\section{Discussion}

We found a high prevalence of C. trachomatis and/or $N$. gonorrhoeae infection among young people attending a community based SRH service in urban and peri-urban Zimbabwe. Notably, only $2.1 \%$ (21/1003) of participants were found to be positive for an STI syndrome and treated accordingly. The prevalence of $C$. trachomatis infection was almost three times higher than the WHO estimates for the African region, but comparable with studies conducted among young women in South Africa $[9,26,29]$. The prevalence of $N$. gonorrhoeae was similar to the recent estimates from the Spectrum-STI model for Zimbabwe of 3.8\% (95\% CI 1.8-6.7\%) [30].

With non-selective testing the number needed to be tested to diagnose an STI was 5.7. This decreased to 4.1 using an STI risk prediction tool cut-point of 19 and 3.5 for a risk prediction tool cut-point of 23. While the STI risk prediction tool with a cut-point of 19 had the desired efficiency of $<60 \%$, the sensitivity was suboptimal at $82 \%$. This is because the prevalence of STIs even among clients with the lowest possible STI risk in this population was relatively high. For example STI prevalence was 5.9\% among those who reported that they had never had sex and $13.9 \%$ among those who only had one lifetime sexual partner. The high STI prevalence among young people without reported risk factors in this population suggests that non-selective testing may be more appropriate than applying a risk prediction tool.
Many recently-published studies show high prevalence of STIs in general African populations but none has developed a risk prediction tool $[13,17,26,27,29$, 31]. To our knowledge, this is the first study globally that has attempted to develop a risk prediction tool in youth, who are a high-risk group for these STIs. A recent Kenyan study among men who have sex with men developed a risk tool for anorectal C. trachomatis and/or $N$. gonorrhoeae infection reaching a sensitivity of $86 \%$ at an efficiency of $61 \%$ [32]. The proposed risk tool came close to the ideal benchmarks for clinical prediction rule performance for STIs of $>90 \%$ sensitivity and $<60 \%$ efficiency $[20,22,23]$. The only study examining the performance of STI risk prediction tools among African women was conducted in 1994 in Tanzania and reported sensitivities between 10 and 29\% which are inadequate [24].

A recent study enrolling Rwandan women in 20162017 compared the performance of a new diagnostic algorithm ('WISH' algorithm) with reference standard diagnostic testing [19]. The WISH algorithm was predefined at the start of the study; women were considered positive according to the algorithm if they met one or more of the following criteria: currently pregnant, exchanged sex for money or goods in the past 12 months, new sexual partner in the past 3 months, or vaginal discharge with an offensive smell or pelvic inflammatory disease observed by a physician. The prevalence of $C$. trachomatis and/or N. gonorrhoeae was $14 \%$ using vaginal swabs investigated by GeneXpert and the sensitivity and efficiency of the WISH algorithm was $75 \%$ and $56 \%$ respectively. While the population in the WISH study is not truly comparable to our study, low sensitivities of both the WISH algorithm and our risk prediction tool would result in missing one in four individuals with STIs using the WISH algorithm and one in six using our risk prediction tool.

A previous study conducted in the same population in Zimbabwe found that only $0.5 \%$ of youth were treated for a STI syndrome and less than $5 \%$ reported symptoms 


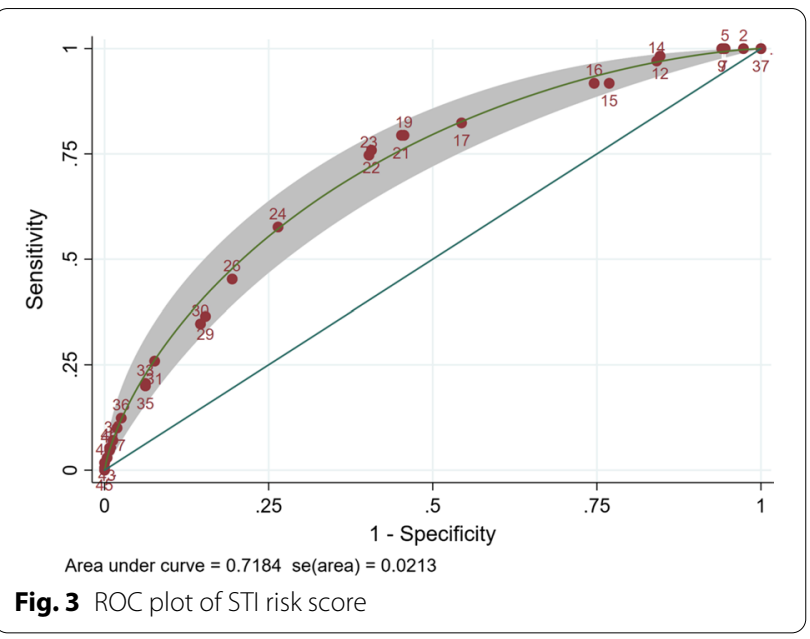

Table 3 Performance of STI risk score at different cut-points

\begin{tabular}{|c|c|c|c|c|}
\hline & \multicolumn{2}{|l|}{ Cutpoint 19} & \multicolumn{2}{|l|}{ Cutpoint 23} \\
\hline & $\%(n / N)$ & $95 \% \mathrm{Cl}$ & $\%(n / N)$ & $95 \% \mathrm{Cl}$ \\
\hline Sensitivity & $82.4 \%(140 / 170)$ & $75.8,87.8$ & $75.9 \%(129 / 170)$ & $68.7,82.1$ \\
\hline Specificity & $45.6 \%$ (359/787) & $42.1,49.2$ & $59.3 \%(467 / 787)$ & $55.8,62.8$ \\
\hline Yield & $24.7 \%(140 / 568)$ & $21.2,28.4$ & $28.7 \%(129 / 449)$ & $24.6,33.2$ \\
\hline Efficiency & $59.4 \%$ (568/957) & $56.2,62.5$ & $46.9 \%$ (449/957) & $43.7,50.1$ \\
\hline NNT & 4.1 & & 3.5 & \\
\hline
\end{tabular}

Efficiency $=$ proportion of population that is tested

NNT $=$ number needed to test to obtain one positive result

when asked specifically [28]. Given the low prevalence of reported symptoms, questions about symptoms were not included in the questionnaire. However the questionnaire used in this study included a broad range of possible risk factors and was informed by studies investigating risk factors for STIs in Africa and STI risk prediction tools developed for high income settings [13, 17, 19-21, 24, 26, 27]. Questions about sexual behaviour are often subject to social desirability bias resulting in underor mis-reporting [33-35]. This may limit the sensitivity of risk prediction tools based on questions about sexual behaviour. While computer-assisted survey instruments rather than self- or interviewer-administered questionnaires may reduce social desirability bias, these may be more difficult to implement in low-resource settings [33-35].

Unsurprisingly STI risk factors in this study were closely associated with each other and with the presence of C. trachomatis and/or N. gonorrhoeae infection in univariable analysis. Due to the co-linearity of risk factors only six independent risk factors were included in the multivariable analysis. The model that was developed was applicable to both sexes even though one risk factor, pregnancy, only applied to women. A sensitivity analysis restricted to women resulted in the same five risk factors for predicting STIs, which is reassuring regarding the robustness of the model. However, we could not conduct a sensitivity analysis for men only given the limited number of men in the study $(n=214)$. This is a limitation of our study, but reflects the reality that men are less likely to access services [36, 37].

The strengths of this study include the large sample size and high participation rate among those opting for STI testing. Also the study was embedded within a population-based SRH service offered in eight communities in two provinces accessed by youth without pre-selection on the basis of STI risk, which makes the findings generalisable to similar settings. We focused on two highly prevalent STIs that cause significant morbidity and mortality. However, we did not include Trichomonas vaginalis, which is highly prevalent especially in women in sub-Saharan Africa [13, 26, 38]. Also for logistic reasons we used urine instead of vaginal swabs. This may have resulted in some STIs being missed.

Importantly we decided against a test and train approach, which is usually used when developing risk prediction tools [39]. This is because our analysis demonstrated that even the most optimal risk prediction tool with a cut-point of 19 was unacceptable.

In view of the high prevalence of STIs among youth in sub-Saharan Africa, non-selective diagnostic testing as opposed to selective testing following the application of a risk prediction tool seems the most promising and appropriate approach. This approach will require true point-ofcare STI diagnostics, which are currently available only for Trichomonas vaginalis and syphilis [40, 41]. While the GeneXpert platform for C. trachomatis and N. gonorrhoeae testing does not require expert skills, is easy to use and widely available in sub-Saharan Africa, the time to result (90 $\mathrm{min}$ ) is prohibitive for the test to be used as a true pointof-care test [42]. However, other molecular tests for chlamydia and gonorrhoea with rapid time to results $(30 \mathrm{~min})$ have been successfully trialled in high-income settings [43]. Universal point-of-care STI testing and immediate single dose treatment for those testing positive should be considered as a strategy for curbing the STI epidemic in youth.

\section{Acknowledgements \\ We would like to thank the Foundation for Innovative New Diagnostics and Cepheid for donation of CT/NG Xpert ${ }^{\circledR}$ cartridges.}

\section{Author's contribution}

KK and RAF conceptualised and designed the study. VS, NR and TB undertook data management and analysis. ED, CDC, CM and MT were responsible for project implementation. AM provided guidance on community STI testing and treatment. RAF, RH and HW conceptualised and designed the parent study (CHIEDZA). IDO and KK oversaw laboratory testing procedures. KK wrote 
the first draft. All authors contributed to writing and reviewing of the manuscript. All authors read and approved the final manuscript.

\section{Funding}

The study was funded by RAF's Wellcome Trust Senior Fellowship 206316_Z_17_Z. IDO received funding though the Wellcome Trust Clinical PhD Programme awarded to the London School of Hygiene and Tropical Medicine (Grant Number 203905/Z/16/Z). The funder had no role in the study design, data collection, data analysis, data interpretation, or writing of the report. The corresponding author had full access to all the data collected and had final responsibility for the decision to submit for publication.

\section{Availability of data and materials}

Individual, anonymised participant data and a data dictionary will be available through The London School of Hygiene and Tropical Medicine repository (Data Compass) 12 months after publication of results. The datasets used and/ or analysed during the current study available from the corresponding author on reasonable request.

\section{Declarations}

\section{Ethics approval and consent to participate}

Written informed consent was obtained from study participants. This study was approved by the LSHTM Research Ethics Committee (16948) and the Medical Research Council of Zimbabwe (MRCZ/A/2387). All methods were carried out in accordance with relevant guidelines and regulations.

\section{Consent for publication}

Not applicable.

\section{Competing interests}

The authors declare no conflict of interest.

\section{Author details}

${ }^{1}$ Clinical Research Department, Faculty of Infectious and Tropical Diseases, London School of Hygiene and Tropical Medicine, London, UK. ${ }^{2}$ Biomedical Research and Training Institute, Harare, Zimbabwe. ${ }^{3}$ Division of Infectious and Tropical Medicine, Medical Centre of the University of Munich, Munich, Germany. ${ }^{4}$ MRC International Statistics and Epidemiology Group, Department of Infectious Disease Epidemiology, London School of Hygiene and Tropical Medicine, London, UK. ${ }^{5}$ Department of Global Health and Infection, Brighton and Sussex Medical School, Brighton, UK. ${ }^{6}$ Department of Public Health and Policy, London School of Hygiene and Tropical Medicine, London, UK. ${ }^{7}$ AIDS and TB Unit, Ministry of Health and Child Care, Harare, Zimbabwe.

\section{Received: 18 September 2021 Accepted: 30 November 2021}

\section{Published online: 08 December 2021}

\section{References}

1. Adachi K, Klausner JD, Xu J, Ank B, Bristow CC, Morgado MG, et al. Chlamydia trachomatis and Neisseria gonorrhoeae in HIV-infected pregnant women and adverse infant outcomes. Pediatr Infect Dis J. 2016;35(8):894900. https://doi.org/10.1097/INF.0000000000001199.

2. Johnson HL, Ghanem KG, Zenilman JM, Erbelding EJ. Sexually transmitted infections and adverse pregnancy outcomes among women attending inner city public sexually transmitted diseases clinics. Sex Transm Dis. 2011;38(3):167-71. https://doi.org/10.1097/OLQ.0b013e3181f2e85f.

3. Warr AJ, Pintye J, Kinuthia J, Drake AL, Unger JA, McClelland RS, et al. Sexually transmitted infections during pregnancy and subsequent risk of stillbirth and infant mortality in Kenya: a prospective study. Sex Transm Infect. 2019;95(1):60-6. https://doi.org/10.1136/sextrans-2018-053597. Epub 2018 Sep 18.

4. Olson-Chen C, Balaram K, Hackney DN. Chlamydia trachomatis and adverse pregnancy outcomes: meta-analysis of patients with and without infection. Matern Child Health J. 2018;22(6):812-21. https://doi.org/ 10.1007/s10995-018-2451-z.

5. Fleming DT, Wasserheit JN. From epidemiological synergy to public health policy and practice: the contribution of other sexually transmitted diseases to sexual transmission of HIV infection. Sex Transm Infect. 1999;75(1):3-17. https://doi.org/10.1136/sti.75.1.3.

6. Ahmadi A, Ramazanzadeh R, Sayehmiri K, Sayehmiri F, Amirmozafari N. Association of Chlamydia trachomatis infections with preterm delivery; a systematic review and meta-analysis. BMC Pregnancy Childbirth. 2018;18(1):240. https://doi.org/10.1186/s12884-018-1868-0.

7. Gottlieb SL, Stoner BP, Zaidi AA, Buckel C, Tran M, Leichliter JS, et al. A prospective study of the psychosocial impact of a positive Chlamydia trachomatis laboratory test. Sex Transm Dis. 2011;38(11):1004-11.

8. Kangas I, Andersen B, Olesen F, Moller JK, Ostergaard L. Psychosocial impact of Chlamydia trachomatis testing in general practice. $\mathrm{Br} J \mathrm{Gen}$ Pract. 2006;56(529):587-93.

9. Rowley J, Vander Hoorn S, Korenromp E, Low N, Unemo M, Abu-Raddad LJ, et al. Chlamydia, gonorrhoea, trichomoniasis and syphilis: global prevalence and incidence estimates, 2016. Bull World Health Organ. 2019;97(8):548-62P. https://doi.org/10.2471/BLT.18.228486 Epub 2019 Jun 6.

10. Dubbink JH, Verweij SP, Struthers HE, Ouburg S, McIntyre JA, Morre SA, et al. Genital Chlamydia trachomatis and Neisseria gonorrhoeae infections among women in sub-Saharan Africa: a structured review. Int J STD AIDS. 2018;29(8):806-24. https://doi.org/10.1177/0956462418758224 Epub 2018 Feb 28

11. Hussen S, Wachamo D, Yohannes Z, Tadesse E. Prevalence of Chlamydia trachomatis infection among reproductive age women in sub Saharan Africa: a systematic review and meta-analysis. BMC Infect Dis. 2018;18(1):596. https://doi.org/10.1186/s12879-018-3477-y.

12. Wall KM, Nyombayire J, Parker R, Ingabire R, Bizimana J, Mukamuyango J, et al. Developing and validating a risk algorithm to diagnose Neisseria gonorrhoeae and Chlamydia trachomatis in symptomatic Rwandan women. BMC Infect Dis. 2021;21(1):392 Epub 2021/04/30.

13. Mudau M, Peters RP, De Vos L, Olivier DH, Mkwanazi DJD, et al. High prevalence of asymptomatic sexually transmitted infections among human immunodeficiency virus-infected pregnant women in a low-income South African community. Int J STD AIDS. 2018;29(4):324-33. https://doi. org/10.1177/0956462417724908 Epub 2017 Aug 11.

14. Semwogerere M, Dear N, Tunnage J, Reed D, Kibuuka H, Kiweewa F, et al. Factors associated with sexually transmitted infections among care-seeking adults in the African Cohort Study. BMC Public Health. 2021;21(1):738 Epub 2021/04/18.

15. Torrone EA, Morrison CS, Chen PL, Kwok C, Francis SC, Hayes RJ, et al. Prevalence of sexually transmitted infections and bacterial vaginosis among women in sub-Saharan Africa: an individual participant data meta-analysis of $18 \mathrm{HIV}$ prevention studies. PLoS Med. 2018;15(2):e1002511.

16. Global health sector strategy on sexually transmitted infections 2016-2021 towards ending STIs. Geneva: World Health Organisation, 2016, https://doi.org/https://apps.who.int/iris/bitstream/handle/10665/246296/WHO-RHR-16.09-eng.pdf? sequence=1. Last accessed 10 May 2020

17. Peters RP, Dubbink JH, van der Eem L, Verweij SP, Bos ML, Ouburg S, et al. Cross-sectional study of genital, rectal, and pharyngeal Chlamydia and gonorrhea in women in rural South Africa. Sex Transm Dis. 2014:41(9):564-9. https://doi.org/10.1097/OLQ.0000000000000175.

18. Romoren M, Sundby J, Velauthapillai M, Rahman M, Klouman E, Hjortdahl P. Chlamydia and gonorrhoea in pregnant Batswana women: time to discard the syndromic approach? BMC Infect Dis. 2007;7:27. https://doi. org/10.1186/471-2334-7-27.

19. Verwijs MC, Agaba SK, Sumanyi JC, Umulisa MM, Mwambarangwe L, Musengamana $V$, et al. Targeted point-of-care testing compared with syndromic management of urogenital infections in women (WISH): a cross-sectional screening and diagnostic accuracy study. Lancet Infect Dis. 2019;19(6):658-69. https://doi.org/10.1016/S473-3099(18)30724-2 Epub 2019 Apr 25.

20. Falasinnu T, Gustafson P, Hottes TS, Gilbert M, Ogilvie G, Shoveller J. A critical appraisal of risk models for predicting sexually transmitted infections. SexTransm Dis. 2014;41(5):321-30. https://doi.org/10.1097/OLQ.00000 00000000120.

21. Falasinnu T, Gilbert M, Gustafson P, Shoveller J. A validation study of a clinical prediction rule for screening asymptomatic chlamydia and gonorrhoea infections among heterosexuals in British Columbia. Sex Transm 
Infect. 2016;92(1):12-8. https://doi.org/10.1136/sextrans-2014-051992 Epub 2015 Apr 30.

22. Hocking J, Fairley CK. Do the characteristics of sexual health centre clients predict chlamydia infection sufficiently strongly to allow selective screening? Sex Health. 2005;2(3):185-92. https://doi.org/10.1071/sh05011.

23. La Montagne DS, Patrick LE, Fine DN, Marrazzo JM. Re-evaluating selective screening criteria for chlamydial infection among women in the US Pacific Northwest. Sex Transm Dis. 2004;31(5):283-9. https://doi.org/10. 1097/01.olq.0000124613.85111.6b.

24. Mayaud P, Uledi E, Cornelissen J, ka-Gina G, Todd J, Rwakatare M, et al. Risk scores to detect cervical infections in urban antenatal clinic attenders in Mwanza, Tanzania. Sex Transm Infect. 1998;74(Suppl 1):S139-46.

25. National STI management guidelines 2019-2021. Zimbabwe Ministry of Health and Child Care, 2019

26. Barnabas SL, Dabee S, Passmore JS, Jaspan HB, Lewis DA, Jaumdally SZ, et al. Converging epidemics of sexually transmitted infections and bacterial vaginosis in southern African female adolescents at risk of HIV. Int J STD AIDS. 2018;29(6):531-9. https://doi.org/10.1177/0956462417740487 Epub 2017 Dec 4.

27. Kaida A, Dietrich JJ, Laher F, Beksinska M, Jaggernath M, Bardsley M, et al. A high burden of asymptomatic genital tract infections undermines the syndromic management approach among adolescents and young adults in South Africa: implications for HIV prevention efforts. BMC Infect Dis. 2018;18(1):499. https://doi.org/10.1186/s12879-018-3380-6.

28. Martin K, Olaru ID, Buwu N, Bandason T, Marks M, Dauya E, et al. Uptake of and factors associated with testing for sexually transmitted infections in community-based settings among youth in Zimbabwe: a mixed-methods study. Lancet Child Adolesc Health. 2020.

29. Garrett NJ, Osman F, Maharaj B, Naicker N, Gibbs A, Norman E, et al. Beyond syndromic management: opportunities for diagnosis-based treatment of sexually transmitted infections in low- and middle-income countries. PLoS One. 2018;13(4):e0196209 eCollection 2018.

30. Korenromp EL, Mahiane G, Rowley J, Nagelkerke N, Abu-Raddad L, Ndowa F, et al. Estimating prevalence trends in adult gonorrhoea and syphilis in low- and middle-income countries with the Spectrum-STI model: results for Zimbabwe and Morocco from 1995 to 2016. Sex Transm Infect. 2017;93(8):599-606. https://doi.org/10.1136/sextrans2016-052953 Epub 2017 Mar 21.

31. Tadesse E, Teshome M, Amsalu A, Shimelis T. Genital Chlamydia trachomatis infection among women of reproductive age attending the gynecology clinic of Hawassa University Referral Hospital, Southern Ethiopia. PLoS One. 2016;11(12):e0168580. https://doi.org/10.1371/journal.pone. eCollection 2016.

32. Quilter LAS, Obondi E, Kunzweiler C, Okall D, Bailey RC, Djomand G, et al. Prevalence and correlates of and a risk score to identify asymptomatic anorectal gonorrhoea and chlamydia infection among men who have sex with men in Kisumu, Kenya. Sex Transm Infect. 2019;95(3):201-11. https://doi.org/10.1136/sextrans-2018-053613 Epub 2018 Sep 21.

33. Beauclair R, Meng F, Deprez N, Temmerman M, Welte A, Hens N, et al. Evaluating audio computer assisted self-interviews in urban South African communities: evidence for good suitability and reduced social desirability bias of a cross-sectional survey on sexual behaviour. BMC Med Res Methodol. 2013;13:11 Epub 2013/02/02.

34. Kelly CA, Soler-Hampejsek E, Mensch BS, Hewett PC. Social desirability bias in sexual behavior reporting: evidence from an interview mode experiment in rural Malawi. Int Perspect Sex Reprod Health. 2013;39(1):14-21 Epub 2013/04/16.

35. Langhaug LF, Cheung YB, Pascoe SJ, Chirawu P, Woelk G, Hayes RJ, et al. How you ask really matters: randomised comparison of four sexual behaviour questionnaire delivery modes in Zimbabwean youth. Sex Transm Infect. 2011;87(2):165-73 Epub 2010/10/15.

36. Takarinda KC, Madyira LK, Mhangara M, Makaza V, Maphosa-Mutsaka M, Rusakaniko S, et al. Factors associated with ever being HIV-tested in Zimbabwe: an extended analysis of the Zimbabwe Demographic and Health Survey (2010-2011). PLoS One. 2016;1 (1):e0147828 Epub 2016/01/26.

37. Dovel K, Dworkin SL, Cornell M, Coates TJ, Yeatman S. Gendered health institutions: examining the organization of health services and men's use of HIV testing in Malawi. J Int AIDS Soc. 2020;23(Suppl 2):e25517 Epub 2020/06/27.

38. Barry MS, Ba Diallo A, Diadhiou M, Mall I, Gassama O, Ndiaye Guèye MD, et al. Accuracy of syndromic management in targeting vaginal and cervical infections among symptomatic women of reproductive age attending primary care clinics in Dakar, Senegal. Trop Med Int Health. 2018;23(5):541-8. https://doi.org/10.1111/tmi.13046 Epub 2018 Mar 26.

39. Ferrand RA, Weiss HA, Nathoo K, Ndhlovu CE, Mungofa S, Munyati S, et al. A primary care level algorithm for identifying HIV-infected adolescents in populations at high risk through mother-to-child transmission. Trop Med Int Health. 2011;16(3):349-55. https://doi.org/10.1111/j.365-3156.2010. 02708.x Epub 2010 Dec 22.

40. Gaydos CA, Klausner JD, Pai NP, Kelly H, Coltart C, Peeling RW. Rapid and point-of-care tests for the diagnosis of Trichomonas vaginalis in women and men. Sex Transm Infect. 2017;93(S4):S31-5. https://doi.org/10.1136/ sextrans-2016-053063 Epub 2017 Jul 6.

41. Pereira LE, McCormick J, Dorji T, Kang J, Sun Y, Shukla M, et al. Laboratory evaluation of a commercially available rapid syphilis test. J Clin Microbiol. 2018;56(10):e00832-18. https://doi.org/10.1128/JCM.-18 Print 2018 Oct.

42. Peeling RW, Mabey D. Point-of-care tests for diagnosing infections in the developing world. Clin Microbiol Infect. 2010;16(8):1062-9.

43. Van Der Pol B, Taylor SN, Mena L, Lebed J, McNeil CJ, Crane L, et al. Evaluation of the performance of a point-of-care test for Chlamydia and Gonorrhea. JAMA Netw Open. 2020;3(5):e204819. https://doi.org/10. 1001/jamanetworkopen.2020.4819.

\section{Publisher's Note}

Springer Nature remains neutral with regard to jurisdictional claims in published maps and institutional affiliations.

\footnotetext{
Ready to submit your research? Choose BMC and benefit from:

- fast, convenient online submission

- thorough peer review by experienced researchers in your field

- rapid publication on acceptance

- support for research data, including large and complex data types

- gold Open Access which fosters wider collaboration and increased citations

- maximum visibility for your research: over $100 \mathrm{M}$ website views per year
}

At BMC, research is always in progress.

Learn more biomedcentral.com/submissions 